\title{
Summarising Historical Text in Modern Languages
}

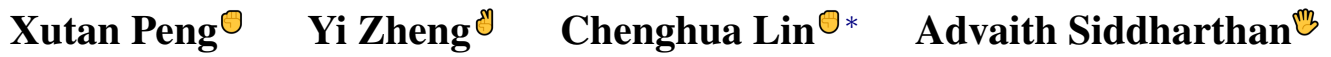 \\ ODepartment of Computer Science, The University of Sheffield, UK \\ I School of Computer Science and Engineering, Beihang University, China \\ ${ }^{3}$ Knowledge Media Institute, The Open University, UK \\ \{x.peng, c.lin\}@shef.ac.uk zhengyi53@buaa.edu.cn \\ advaith.siddharthandopen.ac.uk
}

\begin{abstract}
We introduce the task of historical text summarisation, where documents in historical forms of a language are summarised in the corresponding modern language. This is a fundamentally important routine to historians and digital humanities researchers but has never been automated. We compile a high-quality gold-standard text summarisation dataset, which consists of historical German and Chinese news from hundreds of years ago summarised in modern German or Chinese. Based on cross-lingual transfer learning techniques, we propose a summarisation model that can be trained even with no cross-lingual (historical to modern) parallel data, and further benchmark it against state-of-the-art algorithms. We report automatic and human evaluations that distinguish the historic to modern language summarisation task from standard cross-lingual summarisation (i.e., modern to modern language), highlight the distinctness and value of our dataset, and demonstrate that our transfer learning approach outperforms standard cross-lingual benchmarks on this task.
\end{abstract}

\section{Introduction}

The process of text summarisation is fundamental to research into history, archaeology, and digital humanities (South, 1977). Researchers can better gather and organise information and share knowledge by first identifying the key points in historical documents. However, this can cost a lot of time and effort. On one hand, due to cultural and linguistic variations over time, interpreting historical text can be a challenging and energy-consuming process, even for those with specialist training (Gray et al., 2011). To compound this, historical archives can contain narrative documents on a large scale,

\footnotetext{
${ }^{*}$ Chenghua Lin is the corresponding author.
}

adding to the workload of manually locating important elements (Gunn, 2011). To reduce these burdens, specialised software has been developed recently, such as MARKUS (Ho and Weerdt, 2014) and DocuSky (Tu et al., 2020). These toolkits aid users in managing and annotating documents but still lack functionalities to automatically process texts at a semantic level.

Historical text summarisation can be regarded as a special case of cross-lingual summarisation (Leuski et al., 2003; Orăsan and Chiorean, 2008; Cao et al., 2020), a long-standing research topic whereby summaries are generated in a target language from documents in different source languages. However, historical text summarisation posits some unique challenges. Cross-lingual (i.e., across historical and modern forms of a language) corpora are rather limited (Gray et al., 2011) and therefore historical texts cannot be handled by traditional cross-lingual summarisers, which require cross-lingual supervision or at least large summarisation datasets in both languages (Cao et al., 2020). Further, language use evolves over time, including vocabulary and word spellings and meanings (Gunn, 2011), and historical collections can span hundreds of years. Writing styles also change over time. For instance, while it is common for today's news stories to present important information in the first few sentences, a pattern exploited by modern news summarisers (See et al., 2017), this was not the norm in older times (White, 1998).

In this paper, we address the long-standing need for historical text summarisation through machine summarisation techniques for the first time. We consider the German $\left.\right|_{\mathrm{DE}}$ and Chinese $\left.\right|_{\mathrm{ZH}}$ languages, selected for the following reasons. First, they both have rich textual heritage and accessible (monolingual) training resources for historical and modern language forms. Second, they serve as outstanding representatives of two distinct writing systems (DE 


\begin{tabular}{|c|c|}
\hline $\mathrm{DE}$ & №34 \\
\hline Story & $\begin{array}{l}\text { Jhre Königl. Majest. befinden sich noch vnweit Thorn / ... / dahero zur Erledigung Hoffnung gemacht werden will. } \\
\text { (Their Royal Majesties are still not far from Torn, ... , therefore completion of the hope is desired.) }\end{array}$ \\
\hline Summary & $\begin{array}{l}\text { Der Krieg zwischen Polen und Schweden dauert an. Von einem Friedensvertrag ist noch nicht der Rede. } \\
\text { (The war between Poland and Sweden continues. There is still no talk on the peace treaty.) }\end{array}$ \\
\hline $\mathrm{ZH}$ & №7 \\
\hline Story & $\begin{array}{l}\text { 有脚夫小民，三四千名集众围绕马监丞衙门，..., 冒火突入，捧出敕印。 } \\
\text { (Three to four thousand porters gathered around Majiancheng Yamen (a government office), ..., rushed into fire and } \\
\text { salvaged the authority's seal.) }\end{array}$ \\
\hline Summary & $\begin{array}{l}\text { 小本生意免税条约未能落实, 小商贩被严重剥削, 以致百姓聚众闹事并火烧衙门, 造成多人伤亡。王炀 } \\
\text { 抢救出公章。 } \\
\text { (The tax-exemption act for small businesses was not well implemented and small traders were terribly exploited, } \\
\text { leading to riot and arson attack on Yamen with many casualties. Yang Wang salvaged the authority's seal.) }\end{array}$ \\
\hline
\end{tabular}

Table 1: Examples from our HistSumM dataset.

for alphabetic and ZH for ideographic languages), and investigating them can lead to generalisable insights for a wide range of other languages. Third, we have access to linguistic experts in both languages, for composing high-quality gold-standard modern-language summarises for $\mathrm{DE}$ and $\mathrm{ZH}$ news stories published hundreds of years ago, and for evaluating the output of machine summarisers.

In order to tackle the challenge of a limited amount of resources available for model training (e.g., we have summarisation training data only for the monolingual task with modern languages, and very limited parallel corpora for modern and historical forms of the languages), we propose a transfer-learning-based approach which can be bootstrapped even without cross-lingual supervision. To our knowledge, our work is the first to consider the task of historical text summarisation. As a result, there are no directly relevant methods to compare against. We instead implement two state-of-the-art baselines for standard cross-lingual summarisation, and conduct extensive automatic and human evaluations to show that our proposed method yields better results. Our approach, therefore, provides a strong baseline for future studies on this task to benchmark against.

The contributions of our work are three-fold: (1) we propose a hitherto unexplored and challenging task of historical text summarisation; (2) we construct a high-quality summarisation corpus for historical DE and ZH, with modern DE and ZH summaries by experts, to kickstart research in this field; and (3) we propose a model for historical text summarisation that does not require parallel supervision and provides a validated high-performing baseline for future studies. We release our code and data at https://github.com/Pzoom522/HistSumm.

\section{Related Work}

Processing historical text. Early NLP studies for historical documents focus on spelling normalisation (Piotrowski, 2012), machine translation (Oravecz et al., 2010), and sequence labelling applications, e.g., part-of-speech tagging (Rayson et al., 2007) and named entity recognition (Sydow et al., 2011). Since the rise of neural networks, a broader spectrum of applications such as sentiment analysis (Hamilton et al., 2016), information retrieval (Pettersson et al., 2016), and relation extraction (Opitz et al., 2018) have been developed.

We add to this growing literature in two ways. First, much of the work on historical text processing is focused on English $\left.\right|_{\mid \mathrm{EN}}$, and work in other languages is still relatively unexplored (Piotrowski, 2012; Rubinstein, 2019). Second, the task of historical text summarisation has never been tackled before, to the best of our knowledge. A lack of nonEN annotated historical resources is a key reason for the former, and for the latter, resources do not exist in any language. We hope to spur research on historical text summarisation and in particular for non-EN languages through this work.

Cross-lingual summarisation. The traditional strands of cross-lingual text summarisation systems design pipelines which learn to translate and summarise separately (Leuski et al., 2003; Orăsan and Chiorean, 2008). However, such paradigms suffer from the error propagation problem, i.e., errors produced by upstream modules may accumulate and degrade the output quality (Zhu et al., 2020). In addition, parallel data to train effective translators is not always accessible (Cao et al., 2020). Recently, end-to-end methods have been applied to alleviate this issue. The main challenge for this 
research direction is the lack of direct corpora, leading to attempts such as zero-shot learning (Duan et al., 2019), multi-task learning (Zhu et al., 2019), and transfer learning (Cao et al., 2020). Although training requirements have been relaxed by these methods, our extreme setup with summarisation data only available for the target language and very limited parallel data, has never been visited before.

\section{HistSumm Corpus}

\subsection{Dataset Construction}

In history and digital humanities research, summarisation is most needed when analysing documentary and narrative text such as news, chronicles, diaries, and memoirs (South, 1977). Therefore, for DE we picked the GerManC dataset (Durrell et al., 2012), which contains Optical Character Recognition (OCR) results of DE newspapers from the years 1650-1800. We randomly selected 100 out of the 383 news stories for manual annotation. For ZH, we chose 『万历邸抄』 (Wanli Gazette) as the data source, a collection of news stories from the Wanli period of Ming Dynasty (1573-1620). However, there are no machine-readable versions of Wanli Gazette available; worse still, the calligraphy copies (see Appendix B) are unrecognisable even for non-expert humans, making the OCR technique inapplicable. Therefore, we performed a thorough literature search on over 200 related academic papers and manually retrieved 100 news texts ${ }^{1}$.

To generate summaries in the respective modern language for these historical news stories, we recruited two experts with degrees in Germanistik and Ancient Chinese Literature, respectively. They were asked to produce summaries in the style of DE MLSUM (Scialom et al., 2020) and ZH LCSTS (Hu et al., 2015), whose news stories and summaries are crawled from the Süddeutsche Zeitung website and posts by professional media on the Sina Weibo platform, respectively. The annotation process turned out to be very effort-intensive: for both languages, the experts spent at least 20 minutes in reading and composing a summary for one single news story. The accomplished corpus of 100 news stories and expert summaries in each language, namely HISTSuMm (see examples in Tab. 1), were further examined by six other experts for quality control (see details in $§ 6.2$ ).

\footnotetext{
${ }^{1}$ Detailed references are included in the 'source' entries of ZH HISTSUMM's metadata.
}

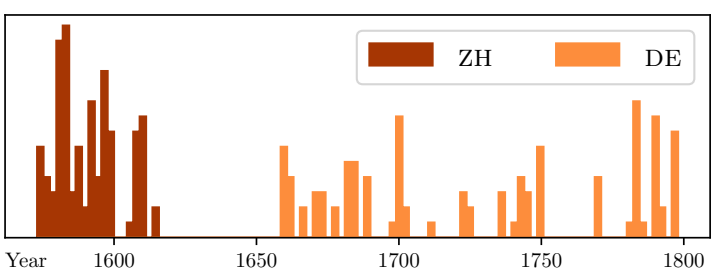

Figure 1: Publication time of HistSumm stories.
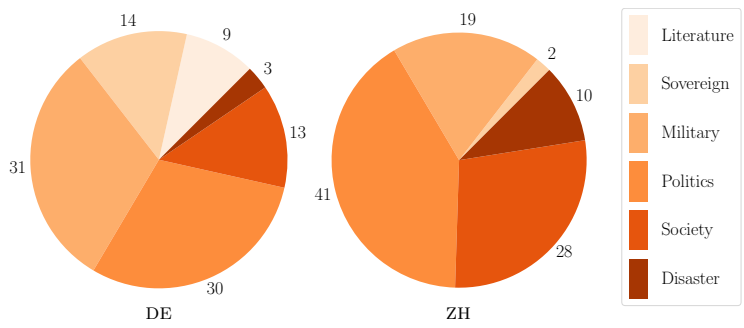

Figure 2: Topic composition of HistSUMM.

\begin{tabular}{l|cc|cc}
\hline & \multicolumn{2}{|c|}{ DE (word-level) } & \multicolumn{2}{c}{ ZH (character-level) } \\
\hline & HISTSUMM & MLSUM & HISTSUMM & LCSTS \\
\hline$L_{\text {story }}$ & 268.1 & 570.6 & 114.5 & 102.5 \\
$L_{\text {summ }}$ & 18.1 & 30.4 & 28.2 & 17.3 \\
$C R(\%)$ & 6.8 & 5.3 & 24.6 & 16.9 \\
\hline
\end{tabular}

Table 2: Comparisons of mean story length ( $\left.L_{\text {story }}\right)$, summary length $\left(L_{\text {summ }}\right)$, and compression rate (CR $\left.=L_{\text {summ }} / L_{\text {story }}\right)$ for summarisation datasets.

\subsection{Dataset Statistics}

Publication time. As visualised in Fig. 1, the publication time of DE and ZH HISTSUMm stories exhibits distinguished patterns. Oldness is an important indicator of the domain and linguistic gaps (Gunn, 2011). Considering news in ZH HISTSUMM is on average 137 years older than its DE counterpart, such gaps can be expected to be greater. On the other hand, DE HISTSUMM stories cover a period of 150 years, compared to just 47 years for $\mathrm{ZH}$, indicating the potential for greater linguistic and cultural variation within the DE corpus.

Topic composition. For a high-level view of HISTSUMM's content, we asked experts to manually classify all news stories into six categories (shown in Fig. 2). We see that the topic compositions of DE and ZH HISTSUMM share some similarities. For instance, Military (e.g., battle reports) and Politics (e.g., authorities' policy and personnel changes) together account for more than half the stories in both languages. On the other hand, we also have language-specific observations. 9\% DE stories are about Literature (e.g., news about book publications), but this topic is not seen in $\mathrm{ZH}$ HistSUMm. And while 14\% DE stories are about 
Sovereign (e.g., royal families and Holy See), there are only 2 examples in ZH (both about the emperor; we found no record on any religious leader in Wanli Gazette). Also, the topics of Society (e.g., social events and judicial decisions) and Natural Disaster (e.g., earthquakes, droughts, and floods) are more prevalent in the $\mathrm{ZH}$ dataset.

Story length. In news summarisation tasks, special attention is paid to the lengths of news stories and summaries (see Tab. 2). Comparing DE HISTSUMM with the corresponding modern corpus DE MLSUM, we find that although historical news stories are on average 53\% shorter, the overall compression rate $(C R \mathrm{~s})$ is quite similar $(6.8 \%$ vs $5.8 \%)$, indicating that key points are summarised to similar extents. Following LCSTS (Hu et al., 2015), the table shows character-level data for $\mathrm{ZH}$, but this is somewhat misleading. While most modern words are double-character, single-character words dominate the historical vocabulary, e.g., the historical word “朋' (friend) becomes “朋友' in modern ZH. According to Che et al. (2016), this leads to a character length ratio of approximately 1:1.6 between parallel historical and modern samples. Taking this into account, the $C R \mathrm{~s}$ for the ZH HISTSUMM and LCSTS datasets are also quite similar to each other.

When contrasting DE with ZH (regardless of historical or modern), we notice that the compression rate is quite different. This might reflect stylistic variations with respect to how verbose news reports are in different languages or by different writers.

\subsection{Vicissitudes of News}

Compared with modern news, articles in HISTSUMM reveal several distinct characteristics with respect to writing style, posing new challenges for machine summarisation approaches.

Lexicon. With social and cultural changes over the centuries, lexical pragmatics of both languages have evolved substantially (Gunn, 2011). For DE, some routine concepts from hundreds of years ago are no longer in use today, e.g., the term 'Brachmonat' (№41), whose direct translation is fallow month, actually refers to June as the cultivation of fallow land traditionally begins in that month (Grimm, 1854). We observe a similar phenomenon in ZH HISTSUMM, e.g., '贡市' (№24 and №31) used to refer to markets that were open to foreign merchants, but is no longer in use. For ZH, additionally, we notice that although some historical words are still in use, their semantics have changed over time, e.g., meaning of '闻' has shifted from hear to smell (№53), and that of '走' has changed from run to walk (№25).

Syntax. Another aspect of language change is that some historical syntax has been abandoned. Consider 'daß derselbe noch länger allda/ biß der Frantz. Abgesandter von dannen widerum abreisen möge/ verbleiben soll' (the same should still remain there for longer, until the France Ambassador might leave again) (№33). We find the subordinate clause is inserted within the main clause, whereas in modern DE it should be 'daß derselbe noch länger allda verbleiben soll, biß der Frantz. Abgesandter von dannen widerum abreisen möge'. For ZH, inversion is common in historical texts but becomes rare in the modern language. For example, sentence '王氏之女成仙者' (Ms. Wang's daughter who became a fairy) (№65) where the attributive adjective is positioned after the head noun, should be '王氏之成仙（的）女' according to modern ZH grammars. Also, we observe cases where historical ZH sentences without constituents such as subjects, predicates, objects, prepositions, etc. In these cases, contexts must be utilised to infer corresponding information, e.g., only by adding '居正' (Juzheng, a minister's name) to the context can we interpret the sentence '已, 又为私书安之云' (№20) as 'after that, (Juzheng) wrote a private letter to comfort him'. This adds extra difficulty to the generation of summaries.

Writing style. To inform readers, a popular practice adopted by modern news writers is to introduce key points in the first one or two sentences (White, 1998). Many machine summarisation algorithms leverage this pattern to enhance summarisation quality by incorporating positional signals (Edmundson, 1969; See et al., 2017; Gui et al., 2019). However, this rhetorical technique was not widely used in HistSumm, where crucial information may appear in the middle or even the end of stories. For instance, the keyword 'Türck' (Turkish) (№33) first occurs in the second half of the story; in article №7 of ZH HISTSUMM (see Tab. 1), only after reading the last sentence can we know the final outcome (i.e., the authority's seal had been saved from fire).

\section{Methodology}

Based on the popular cross-lingual transfer learning framework of (Ruder et al., 2019), we propose 
a simple historical text summarisation framework (see Fig. 3), which can be trained even without supervision (i.e., parallel historical-modern signals).

Step 1. For both DE and ZH, we begin with respectively training modern and historical monolingual word embeddings. Specially, for DE, following the suggestions of Wang et al. (2019), we selected subword-based embedding algorithms (e.g., FastText (Joulin et al., 2017)) as they yield competitive results. In addition to training word embeddings on the raw text, for historical DE we also consider performing text normalisation (NORM) to enhance model performance. This orthographic technique aims to convert words from their historical spellings to modern ones, and has been widely adopted as a standard step by NLP applications for historical alphabetic languages (Bollmann, 2019). Although training a normalisation model in a fully unsupervised setup is not yet realistic, it can get bootstrapped with a single lexicon table to yield satisfactory performance (Ljubešić et al., 2016; Scherrer and Ljubešić, 2016).

For ideographic languages like $\mathrm{ZH}$, word embeddings trained on stroke signals (which is analogous to subword information of alphabetic languages) achieve state-of-the-art performance (Cao et al., 2018), so we utilise them to obtain monolingual vectors. Compared with simplified characters (which dominate our training resources), traditional ones typically provide much richer stroke signals and thus benefit stroke-based embeddings (Chen and Sheng, 2018), e.g., traditional '葉' (leaf) contains semantically related components of ' + , (plant) and '木' (wood), while its simplified version ('叶') does not.

Therefore, to improve the model performance we also conduct additional experiments on enhanced corpora which are converted to the traditional glyph using corresponding rules (CONV) (see $\S 5.3$ for further details).

Step 2. Next, we respectively build two semantic spaces for DE and ZH, each of which is shared by historical and modern word vectors. This approach, namely cross-lingual word embedding mapping, aligns different embedding spaces using linear projections (Artetxe et al., 2018; Ruder et al., 2019). Given parallel supervision is very limited in realworld scenarios, we mainly consider two bootstrapping strategies: in a fully unsupervised (UspMap) style and through identical lexicon pairs (IdMap).

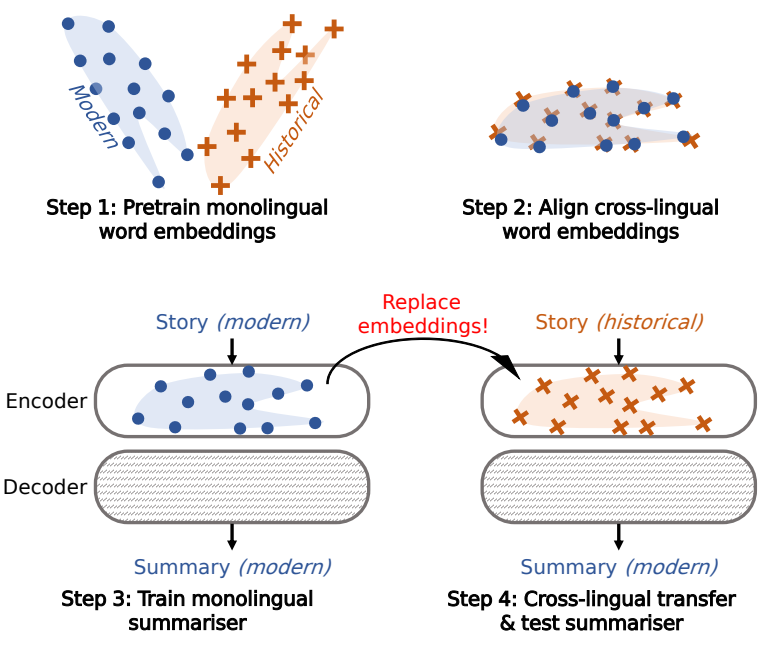

Figure 3: Illustration of our proposed framework.

While the former only relies on topological similarities between input vectors, the latter additionally takes advantage of words in the intersected vocabulary as seeds. Although their historical and current meanings can differ (cf. § 3.3), in most cases they are similar, providing very weak parallel signals (e.g., 'Krieg' (war) and 'Frieden' (peace) are common to historical and modern DE; '天' (universe) and '人' (human) to historical and modern $\mathrm{ZH}$ ).

Step 3. In this step, for each of DE and ZH we use a large monolingual modern-language summarisation dataset to train a basic summariser that only takes modern-language inputs. Embedding weights of the encoder are initialised with the modern partition of corresponding cross-lingual word vectors in Step 2 and are frozen during the training process, while those of the decoder are randomly initialised and free to update through back-propagation.

Step 4. Upon convergence in the last step, we directly replace the embedding weights of the encoder with the historical vectors in the shared vector space, yielding a new model that can be fed with historical inputs but output modern sentences. This entire process does not require any external parallel supervision.

\section{Experimental Setup}

\subsection{Training Data}

Consistent with $\S 3.1$, we selected DE MLSUM and ZH LCSTS as monolingual summarisation training sets. For monolingual corpora for word embedding training, to minimise temporal and domainal variation, we only considered datasets that were similar 
to articles in MLSUM, LCSTS, and HISTSUMM, i.e, with text from comparable periods and centred around news-related domains.

For modern DE, such resources are easy to access: we directly downloaded the DE News Crawl Corpus released by WMT 2014 workshops (Bojar et al., 2014), which contains shuffled sentences from online news sites. We then conducted tokenisation and removed noise such as emojis and links. For historical DE, besides the already included GerManC corpus, we also saved Deutsches Textarchiv (Nolda, 2019), MercuriusBaumbank (Ulrike, 2020), and Mannheimer Korpus (Mannheim, 2020) as training data. Articles in these datasets are all relevant to news and have topics such as Society and Politics. Note that we only preserved documents written in 1600 to 1800 to match the publication time of DE HISTSUMM stories (cf. § 3.2). Apart from the standard data cleaning procedures (tokenisation and noise removal, as mentioned above), for historical DE corpora we replaced the very common slash symbols (/) with their modern equivalents: commas (,) (Lindemann, 2015). We also lower-cased letters and deleted sentences with less than 10 words, yielding $505 \mathrm{~K}$ sentences and $12 \mathrm{M}$ words in total.

For modern $\mathrm{ZH}$, we further collected news articles in the corpora released by $\mathrm{He}$ (2018), Hua et al. (2018), and Xu et al. (2020) to train better embeddings. For historical $\mathrm{ZH}$, to the best of our knowledge, there is no standalone Ming Dynasty news collection except Wanli Gazette. Therefore, from the resources released by Jiang et al. (2020), we retrieved Ming Dynasty articles belonging to categories $^{2}$ of Novel, History/Geography, and Mili$\operatorname{tary}^{3}$. Raw historical ZH text does not have punctuation marks, so we first segmented sentences using the Jiayan Toolkit ${ }^{4}$. Although Jiayan supports tokenisation, we skipped this step as the accuracy is unsatisfactory. Given that a considerable amount of historical ZH words only have one character (cf. $\S 3.2$ and $\S 3.3$ ), following Li et al. (2018) we simply treated characters as basic units during training. Analogous to historical DE, we removed sentences with less than 10 characters. The remaining corpus has $992 \mathrm{k}$ sentences and $28 \mathrm{M}$ characters.

\footnotetext{
${ }^{2}$ Following the topic taxonomy of Jiang et al. (2020).

${ }^{3}$ Sampling inspection confirmed that their domains are similar to those of Wanli Gazette.

${ }^{4}$ https://github.com/jiaeyan/Jiayan
}

\subsection{Baseline Approaches}

In addition to the proposed method, we also consider two strong baselines based on the Cross-lingual Language Modelling paradigm (XLM) (Lample and Conneau, 2019), which has established state-of-the-art performance in the standard cross-lingual summarisation task (Cao et al., 2020). More concretely, for DE and ZH respectively, we pretrain baselines on all available historical and modern corpora using causal language modelling and masked language modelling tasks. Next, they are respectively fine-tuned on modern text summarisation and unsupervised machine translation tasks. The former becomes the (XLM-E2E) baseline, which can be directly executed on HISTSUMM in an end-to-end fashion; the latter (XLM-Pipe) is coupled with the basic summariser for modern inputs in Step 3 of $\S 4$ to form a translate-thensummarise pipeline.

\subsection{Model Configurations}

Normalisation and convention. We normalised historical DE text using cSMTiser (Ljubešić et al., 2016; Scherrer and Ljubešić, 2016), which is based on character-level statistical machine translation. Following the original papers, we pretrained the normaliser using RIDGES corpus (Odebrecht et al., 2017). As for the $\mathrm{ZH}$ character convention, we utilised the popular OpenCC ${ }^{5}$ project which uses a hard-coded lexicon table to convert simplified input characters into their traditional forms.

Word embedding. As discussed in $\S 4$, when training DE and ZH monolingual embeddings, we respectively ran subword-based FastText (Joulin et al., 2017) and stroke-based Cw2 Vec (Cao et al., 2018). For both languages, we set the dimension at 100 and learned embeddings for all available tokens (i.e., mincount $=1$ ). Other hyperparameters followed the default configurations. After training, we preserved the most frequent $50 \mathrm{~K}$ tokens in each vocabulary (NB: historical ZH only has $13 \mathrm{~K}$ unique tokens). To obtain aligned spaces for modern and historical vectors, we then utilised the robust VecMap framework (Artetxe et al., 2018) with its original settings.

Summarisation model. We implemented our main model based on the robust Pointer-Generator Network (See et al., 2017), which is a hybrid framework for extractive (to copy source expressions

\footnotetext{
${ }^{5}$ https://github.com/BYVoid/OpenCC
} 


\begin{tabular}{|c|c|c|c|}
\hline$\overline{\mathrm{DE}}$ & ROUGE-1 & ROUGE-2 & ROUGE-L \\
\hline$\overline{\text { XLM-Pipe }}$ & 12.72 & 2.88 & 10.67 \\
\hline$X L M-E 2 E$ & 13.48 & 3.27 & 11.25 \\
\hline Üsp'pāp & $13 . \overline{3} 6$ & $\overline{3} . \overline{0} 2$ & $\overline{1} 1 . \overline{2}$ \\
\hline UspMap+NORM & 13.78 & 3.59 & 11.60 \\
\hline IdMap & 13.45 & 3.10 & 11.38 \\
\hline IdMap+NORM & 14.37 & 3.30 & 12.14 \\
\hline \multicolumn{4}{|l|}{$\mathrm{ZH}$} \\
\hline XLM-Pipe & 10.91 & 2.96 & 9.83 \\
\hline$X L M-E 2 E$ & 12.67 & 3.86 & 11.02 \\
\hline ŪspMàp & $13 . \overline{0} 9$ & $\overline{4} . \overline{2} 5$ & $\overline{1} 1 . \overline{3} \overline{1}$ \\
\hline UspMap+CONV & 16.38 & 6.06 & 14.00 \\
\hline IdMap & 18.38 & 7.05 & 15.89 \\
\hline IdMap+CONV & 19.22 & 7.42 & 16.52 \\
\hline
\end{tabular}

Table 3: ROUGE F1 scores (\%) on HISTSUMM.

\begin{tabular}{|c|c|c|c|}
\hline $\mathrm{EN} \rightarrow \mathrm{ZH}$ & ROUGE-1 & ROUGE-2 & ROUGE-L \\
\hline XLM-Pipe & 14.93 & 4.14 & 12.62 \\
\hline$X L M-E 2 E$ & 18.02 & 5.10 & 15.39 \\
\hline$\overline{\mathrm{U}} \overline{\mathrm{spM}} \overline{\mathrm{p}} \overline{\mathrm{ap}}$ & $\overline{11} . \overline{4} 3$ & $\overline{1} . \overline{2} 7^{-}$ & $\overline{10} \overline{0.0 \overline{7}}$ \\
\hline IdMap & 12.06 & 1.72 & 10.93 \\
\hline \multicolumn{4}{|l|}{$\overline{\mathrm{ZH} \rightarrow \mathrm{EN}}$} \\
\hline XLM-Pipe & 9.08 & 3.29 & 7.43 \\
\hline$X L M-E 2 E$ & 12.97 & 4.31 & 10.95 \\
\hline$\overline{\mathrm{U}} \overline{\mathrm{spM}} \overline{\mathrm{p}} \overline{\mathrm{p}} \overline{\mathrm{s}}$ & $\overline{5} . \overline{15}$ & $\overline{0} . \overline{8} 4$ & $\overline{2} . \overline{4} 2^{-}$ \\
\hline IdMap & 5.98 & 1.33 & 2.90 \\
\hline
\end{tabular}

Table 4: ROUGE F1 scores (\%) of standard crosslingual summarisation. Following Cao et al. (2020), for monolingual pretraining, we used corpora in $\S 5.3$ (57M sentences) for modern $\mathrm{ZH}$ and annotated Gigaword (Napoles et al., 2012) (183M sentences) for EN; for summarisation training, we used LCSTS for $\mathrm{EN} \rightarrow \mathrm{ZH}$ and CNN/DM dataset (Hermann et al., 2015) for $\mathrm{ZH} \rightarrow \mathrm{EN}$; for testing, we used the data released by Zhu et al. (2019).

via pointing) and abstractive (to produce novel words) summarisation models. After setting up the encoder and decoder (cf. in Step 3 of $\S 4$ ), we started training with the default configurations. As for the two baselines which are quite heavyweight (XLM (Lample and Conneau, 2019) is based on BERT (Devlin et al., 2019) and has 250M valid parameters), we trained them from scratch with FP16 precision due to moderate computational power access. All other hyperparameter values followed the official XLM settings. To ensure the baselines can yield their highest possible performance, we trained them on the enhanced corpora, i.e., normalised DE (NORM) and converted ZH (CONV).

\section{Results and Analyses}

\subsection{Automatic Evaluation}

We assessed all models with the standard ROUGE metric (Lin, 2004), reporting F1 scores for ROUGE-1, ROUGE-2, and ROUGE-L. Following
Hu et al. (2015), the ROUGE score of ZH outputs are calculated on character-level.

As shown in Tab. 3, for DE, our proposed methods are comparable to the baseline approaches or outperform the baselines by small amounts; for $\mathrm{ZH}$, our models are superior by large margins. Given that XLM-based models require a lot more training resources than our model, we consider this a positive result. For comparison of the strengths and weaknesses of the models, we show their performance for a modern cross-lingual summarisation task in Tab. 4. To heighten the contrast we chose two languages (ZH and EN) from different families and with minimal overlap of vocabulary. As shown in Tab. 4, the XLM-based models outperform our method on this modern language cross-lingual summarisation task by large margins.

The difference in the performance of models on the modern and historical summarisation tasks illustrate key differences in the tasks and also some of the shortcomings of the models. Firstly, the great temporal gap (up to 400 years for DE and 600 years for $\mathrm{ZH}$ ) between our historical and modern data hurts the XLM paradigm, which relies heavily on the similarity between corpora (Kim et al., 2020). In addition, Kim et al. (2020) also show that inadequate monolingual data size (less than $1 \mathrm{M}$ sentences) is likely to lead to unsatisfactory performance of XLM, even for etymologically close language pairs such as EN-DE. In our experiments we only have $505 \mathrm{~K}$ and $992 \mathrm{~K}$ sentences for historical DE and $\mathrm{ZH}$ (cf. § 5.1). On the other hand, considering the negative influence of the error-propagation issue (cf. $\S 2$ ), the poor performance of XLM-Pipe is not surprising and is in line with observations of Cao et al. (2020) and Zhu et al. (2020). Our model instead makes use of cross-lingual embeddings, including bootstrapping from identical lexicon pairs. This approach helps overcome data sparsity issues for the historical summarisation tasks and is also successful at leveraging the similarities in the language pairs. However, its performance drops when the two languages are as far apart as EN and ZH.

When analysing the ablation results of the proposed method, on DE and ZH we found different trends. For DE, scores achieved by all the four setups show minor variance. To be specific, models bootstrapped with identical word pairs outperformed the unsupervised ones, and models trained on normalised data yielded stronger performance. 


\begin{tabular}{|c|c|c|c|c|}
\hline$\overline{\mathrm{DE}}$ & Informativeness & Conciseness & Fluency & Currentness \\
\hline Expert & $4.85(.08)$ & $5.00(.00)$ & $4.94(.03)$ & $4.99(.00)$ \\
\hline $\bar{X} \overline{\mathrm{L}} \overline{\mathrm{M}}-\overline{\mathrm{E}} \overline{\mathrm{E}} \overline{\mathrm{E}}$ & $\overline{2} . \overline{2} 6 \overline{(} . \overline{2} 0 \overline{)}$ & $2 . \overline{35}(.2 \overline{4})$ & $\overline{3.3 \overline{4}}(.1 \overline{9})$ & $\overline{3} . \overline{67}(. \overline{23})$ \\
\hline UspMap+NORM & $2.51(.18)$ & $2.53(.22)$ & $3.28(.22)$ & $3.64(.24)$ \\
\hline IdMap+NORM & $2.52(.18)$ & $\mathbf{2 . 5 4}(.20)$ & $3.32(.28)$ & $\mathbf{3 . 7 2}(.24)$ \\
\hline \multicolumn{5}{|l|}{$\overline{\mathrm{ZH}}$} \\
\hline \multicolumn{5}{|c|}{4.72} \\
\hline $\bar{X} \overline{\mathrm{L}} \overline{\mathrm{M}}-\overline{\mathrm{E}} \overline{2 \mathrm{E}}$ & $\overline{2} . \overline{18} \overline{(.23)}$ & $2 . \overline{2} \overline{1}(. \overline{2} \overline{7})$ & $\overline{\mathbf{2 . 8 0}}(.2 \overline{2})$ & $\overline{2.53} \overline{(.23)} \overline{-}$ \\
\hline IdMap & $2.39(.19)$ & $2.49(.26)$ & $2.66(.25)$ & $2.50(.23)$ \\
\hline IdMap+CONV & $2.37(.21)$ & $\mathbf{2 . 5 7}(.28)$ & $2.78(.24)$ & $\mathbf{2 . 5 9}(.25)$ \\
\hline
\end{tabular}

Table 5: Average human ratings on HISTSUMM (variance is in parentheses).

Among all tested versions, UspMap+NORM got the best score in ROUGE-2 and IdMap+NORM led in ROUGE-1 and ROUGE-L, indicating that the normalisation enhancement does benefit DE historical text summarisation models. For ZH, as predicted, with richer glyph information encoded, the stroke-based embedding method can better learn word semantics. We find that UspMap+CONV outperforms UspMap and IdMap+CONV outperforms IdMap. Adding identical words during mapping initialisation brings substantial benefits too: $3.58 \%$ and $2.52 \%$ ROUGE-L improvement for IdMap over UspMap and IdMap+CONV over UspMap+CONV, respectively.

\subsection{Human Judgement}

To gain further insights, we invited six experts to conduct human evaluations. Like the annotators in $\S 3.1$, they also held degrees in Germanistik or Ancient Chinese Literature. Beyond the standard dimensions of summarisation evaluation (Informativeness, Conciseness, and Fluency), we added 'Currentness' as the fourth, which focuses on measuring 'to what extent a summary follows current rather than early linguistic styles'. We used a five-point Likert scale, with 1 for worst and 5 for best. For each language, experts were only asked to rate the gold-standard human summary and the summaries generated by the XLM-E2E baseline and the best two setups in $\S 6.1$. For each of the 100 news stories in each language, 3 experts independently each rated the three model outputs and the human summary.

The final results are given in Tab. 5. When comparing different systems, we report statistical significance as the $p$-value of two-tailed t-tests with Bonferroni correction (Dror et al., 2018). We found that in all aspects the scores for the goldstandard summaries were always above 4 points, indicating the high quality of the gold-standard summaries. Across both languages, our models outperform the baseline for informativeness and conciseness $(p<0.01)$ and achieve comparable levels of fluency and currentness. Summaries generated by XLM-E $2 \mathrm{E}$ were slightly more fluent than our approach for both DE and ZH $(p<0.05)$, indicating that the baseline has merit with respect to its language modelling abilities. However, it tended to make errors in understanding historical inputs and locating key points; e.g. the human reference for ZH article №57 is focused on the commander's decision of bursting the river to beat the rebel army ( ‘宁夏之役中, 魏学曾为了击溃叛乱部落, 决定决河灌城'), but XLM-E2E summarises it as 黄河大堤水, 比塔顶还高几丈' (the surface of the river is several feet higher than the tower top), which is fluent but irrelevant.

As for different setups of the proposed algorithm, for DE, in dimensions of Informativeness, Conciseness and Fluency, the performance of UspMap+Norm and IdMap+NORM was almost equally good. The improvement from utilising identical word pairs for cross-lingual word embedding mapping seems more evident for Currentness, i.e., the average score was 0.08 higher $(p<0.05)$. For ZH, while IdMap and IdMap+CONV achieved close Informativeness scores, the latter outperforms the former in other three aspects by $0.08,0.12$, and 0.09 respectively $(p<0.01)$. This observation indicates that when the lexical encoding is improved with enriched stroke-level information, the model is less likely to include redundant information in the summaries (i.e., conciseness score is higher), and the produced sentences are more fluent in terms of modern $\mathrm{ZH}$ grammars (see output examples in Appendix A).

\subsection{Error Analysis}

We further analysed model inputs with the lowest scores in $\S 6.2$, and found that they were mostly for stories whose content was dissimilar to any sample in modern training sets. For instance, five ZH 
texts in HISTSUmm are on themes not seen in modern news (i.e., witchcraft (№65), monsters (№35 and №46), and abnormal astromancy (№8 and №28)). On these texts, even the best-performing IdMap+CONV model outputs a large number of [UNK] tokens and can merely achieve average Informativeness, Conciseness, Fluency, and Correctness scores of $1.41,1.67,1.83$, and 1.60 respectively, which are significantly below its overall results in Tab. 5. This reveals the current system's shortcoming when processing inputs with themelevel zero-shot patterns. This issue is typically ignored in the cross-lingual summarisation literature due to the rarity of such cases in modern language tasks. However, we argue that a key contribution of our proposed task and dataset is that they together indicate new improvement directions beyond standard cross-lingual summarisation studies, such as the challenges of zero-shot generalisation and historical linguistic gaps (cf. § 3.3).

\section{Conclusion and Future Work}

This paper introduced the new task of summarising historical documents in modern languages, a previously unexplored but important application of cross-lingual summarisation that can support historians and digital humanities researchers. To facilitate future research on this topic, we constructed the first summarisation corpus for historical news in DE and ZH using linguistic experts. We also proposed an elegant transfer learning method that makes effective use of similarities between languages and therefore requires limited or even zero parallel supervision. Our automatic and human evaluations demonstrated the strengths of our method over state-of-the-art baselines. This paper is the first study of automated historical text summarisation. In the future, we will improve our models to address the issues highlighted in this study (e.g. zero-shot patterns and language change), add further languages (e.g., English and Greek), and increase the size of the dataset in each language.

\section{Acknowledgements}

This work is supported by the award made by the UK Engineering and Physical Sciences Research Council (Grant number: EP/P011829/1) and Baidu, Inc. Neptune.ai generously offered us a team license to facilitate experiment tracking.

We would like to express our sincerest gratitude to Qirui Zhang, Qingyi Sha, Xia Wu, Yu Hu, Silu
Ding, Beiye Dai, Xingyan Zhu, and Juecheng Lin, who are all from Nanjing University, for manually annotating and validating the HISTSUMM corpus. We also thank Guanyi Chen, Ruizhe Li, Xiao Li, Shun Wang, Zhiang Chen, and the anonymous reviewers for their insightful and helpful comments.

\section{References}

Mikel Artetxe, Gorka Labaka, and Eneko Agirre. 2018. A robust self-learning method for fully unsupervised cross-lingual mappings of word embeddings. In Proceedings of the 56th Annual Meeting of the Association for Computational Linguistics (Volume 1: Long Papers), pages 789-798.

Ondřej Bojar, Christian Buck, Christian Federmann, Barry Haddow, Philipp Koehn, Johannes Leveling, Christof Monz, Pavel Pecina, Matt Post, Herve Saint-Amand, Radu Soricut, Lucia Specia, and Aleš Tamchyna. 2014. Findings of the 2014 workshop on statistical machine translation. In Proceedings of the Ninth Workshop on Statistical Machine Translation, pages 12-58, Baltimore, Maryland, USA. Association for Computational Linguistics.

Marcel Bollmann. 2019. A large-scale comparison of historical text normalization systems. In Proceedings of the 2019 Conference of the North American Chapter of the Association for Computational Linguistics: Human Language Technologies, Volume 1 (Long and Short Papers), pages 3885-3898, Minneapolis, Minnesota. Association for Computational Linguistics.

Shaosheng Cao, Wei Lu, Jun Zhou, and Xiaolong Li. 2018. Cw2Vec: Learning Chinese word embeddings with stroke n-grams. In Proceedings of the 32th AAAI Conference on Artificial Intelligence. AAAI.

Yue Cao, Hui Liu, and Xiaojun Wan. 2020. Jointly learning to align and summarize for neural crosslingual summarization. In Proceedings of the 58th Annual Meeting of the Association for Computational Linguistics, pages 6220-6231, Online. Association for Computational Linguistics.

Chao Che, Wenwen Guo, and Jianxin Zhang. 2016. Sentence alignment method based on maximum entropy model using anchor sentences. In Chinese Computational Linguistics and Natural Language Processing Based on Naturally Annotated Big Data, pages 76-85, Cham. Springer International Publishing.

Wenfan Chen and Weiguo Sheng. 2018. A hybrid learning scheme for Chinese word embedding. In Proceedings of The Third Workshop on Representation Learning for NLP, pages 84-90, Melbourne, Australia. Association for Computational Linguistics. 
Jacob Devlin, Ming-Wei Chang, Kenton Lee, and Kristina Toutanova. 2019. BERT: Pre-training of deep bidirectional transformers for language understanding. In Proceedings of the 2019 Conference of the North American Chapter of the Association for Computational Linguistics: Human Language Technologies, Volume 1 (Long and Short Papers), pages 4171-4186, Minneapolis, Minnesota. Association for Computational Linguistics.

Rotem Dror, Gili Baumer, Segev Shlomov, and Roi Reichart. 2018. The hitchhiker's guide to testing statistical significance in natural language processing. In Proceedings of the 56th Annual Meeting of the Association for Computational Linguistics (Volume 1: Long Papers). Association for Computational Linguistics.

Xiangyu Duan, Mingming Yin, Min Zhang, Boxing Chen, and Weihua Luo. 2019. Zero-shot crosslingual abstractive sentence summarization through teaching generation and attention. In Proceedings of the 57th Annual Meeting of the Association for Computational Linguistics, pages 3162-3172, Florence, Italy. Association for Computational Linguistics.

Martin Durrell, Paul Bennett, Silke Scheible, and Richard J. Whitt. 2012. GerManC. Oxford Text Archive.

H. P. Edmundson. 1969. New methods in automatic extracting. Journal of the ACM, 16(2):264-285.

Russell D Gray, Quentin D Atkinson, and Simon J Greenhill. 2011. Language evolution and human history: what a difference a date makes. Philosophical Transactions of the Royal Society B: Biological Sciences.

Jacob Grimm. 1854. Deutsches Wörterbuch. Hirzel.

Min Gui, Junfeng Tian, Rui Wang, and Zhenglu Yang. 2019. Attention optimization for abstractive document summarization. In Proceedings of the 2019 Conference on Empirical Methods in Natural Language Processing and the 9th International Joint Conference on Natural Language Processing (EMNLP-IJCNLP), pages 1222-1228, Hong Kong, China. Association for Computational Linguistics.

S. Gunn. 2011. Research Methods for History. Research Methods for the Arts and Humanities Series. Edinburgh University Press.

William L. Hamilton, Kevin Clark, Jure Leskovec, and Dan Jurafsky. 2016. Inducing domain-specific sentiment lexicons from unlabeled corpora. In Proceedings of the 2016 Conference on Empirical Methods in Natural Language Processing, pages 595-605, Austin, Texas. Association for Computational Linguistics.

Zhengfang He. 2018. Chinese short text summarization dataset.
Karl Moritz Hermann, Tomas Kocisky, Edward Grefenstette, Lasse Espeholt, Will Kay, Mustafa Suleyman, and Phil Blunsom. 2015. Teaching machines to read and comprehend. In C. Cortes, N. D. Lawrence, D. D. Lee, M. Sugiyama, and R. Garnett, editors, Advances in Neural Information Processing Systems 28, pages 1693-1701. Curran Associates, Inc.

Hou Ieong Brent Ho and Hilde De Weerdt. 2014. MARKUS. Text Analysis and Reading Platform. Funded by the European Research Council and the Digging into Data Challenge.

Baotian Hu, Qingcai Chen, and Fangze Zhu. 2015. LCSTS: A large scale Chinese short text summarization dataset. In Proceedings of the 2015 Conference on Empirical Methods in Natural Language Processing, pages 1967-1972, Lisbon, Portugal. Association for Computational Linguistics.

Lifeng Hua, Xiaojun Wan, and Lei Li. 2018. Overview of the NLPCC 2017 shared task: Single document summarization. In Natural Language Processing and Chinese Computing, pages 942-947, Cham. Springer International Publishing.

Yan-ting Jiang, Yu-ting Pan, and Le Yang. 2020. A research on verbal classifiers collocation in premodern Chinese based on statistics and word embedding. In Journal of Xihua University (Philosophy \& Social Sciences).

Armand Joulin, Edouard Grave, Piotr Bojanowski, and Tomas Mikolov. 2017. Bag of tricks for efficient text classification. In Proceedings of the 15th Conference of the European Chapter of the Association for Computational Linguistics: Volume 2, Short Papers, pages 427-431, Valencia, Spain. Association for Computational Linguistics.

Yunsu Kim, Miguel Graça, and Hermann Ney. 2020. When and why is unsupervised neural machine translation useless? In Proceedings of the 22nd Annual Conference of the European Association for Machine Translation, pages 35-44, Lisboa, Portugal. European Association for Machine Translation.

Guillaume Lample and Alexis Conneau. 2019. Crosslingual language model pretraining. Advances in Neural Information Processing Systems (NeurIPS).

Anton Leuski, Chin-Yew Lin, Liang Zhou, Ulrich Germann, Franz Josef Och, and Eduard Hovy. 2003. Cross-lingual c*st*rd: English access to Hindi information. ACM Transactions on Asian Language Information Processing (TALIP), 2(3):245-269.

Shen Li, Zhe Zhao, Renfen Hu, Wensi Li, Tao Liu, and Xiaoyong Du. 2018. Analogical reasoning on Chinese morphological and semantic relations. In Proceedings of the 56th Annual Meeting of the Association for Computational Linguistics (Volume 2: Short Papers), pages 138-143. Association for Computational Linguistics. 
Chin-Yew Lin. 2004. ROUGE: A package for automatic evaluation of summaries. In Text Summarization Branches Out, pages 74-81, Barcelona, Spain. Association for Computational Linguistics.

Mary Lindemann. 2015. A Ruler's Consort in Early Modern Germany: Aemilia Juliana of SchwarzburgRudolstadt. German History, 33(2):291-292.

Nikola Ljubešić, Katja Zupan, Darja Fišer, and Tomaž Erjavec. 2016. Normalising Slovene data: historical texts vs. user-generated content. In Proceedings of the 13th Conference on Natural Language Processing (KONVENS 2016), pages 146-155.

IDS Mannheim. 2020. Mannheimer Korpus Historischer Zeitungen und Zeitschriften (Version 1.0). Institut für Deutsche Sprache Mannheim.

Courtney Napoles, Matthew Gormley, and Benjamin Van Durme. 2012. Annotated gigaword. In Proceedings of the Joint Workshop on Automatic Knowledge Base Construction and Web-Scale Knowledge Extraction, AKBC-WEKEX '12, page 95-100, USA. Association for Computational Linguistics.

Andreas Nolda. 2019. Deutsches Textarchiv (1600-1900). Berlin-Brandenburg Academy of Sciences and Humanities (BBAW).

Carolin Odebrecht, Malte Belz, Amir Zeldes, Anke Lüdeling, and Thomas Krause. 2017. Ridges herbology: designing a diachronic multi-layer corpus. Language Resources and Evaluation, 51(3):695725 .

Juri Opitz, Leo Born, and Vivi Nastase. 2018. Induction of a large-scale knowledge graph from the Regesta Imperii. In Proceedings of the Second Joint SIGHUM Workshop on Computational Linguistics for Cultural Heritage, Social Sciences, Humanities and Literature, pages 159-168, Santa Fe, New Mexico. Association for Computational Linguistics.

Constantin Orăsan and Oana Andreea Chiorean. 2008. Evaluation of a cross-lingual Romanian-English multi-document summariser. In Proceedings of the Sixth International Conference on Language Resources and Evaluation (LREC'08), Marrakech, Morocco.

Csaba Oravecz, Bálint Sass, and Eszter Simon. 2010. Semi-automatic normalization of old Hungarian codices. In Proceedings of the ECAI 2010 Workshop on Language Technology for Cultural Heritage, Social Sciences, and Humanities (LaTeCH 2010), pages 55-59.

Eva Pettersson, J. Lindström, B. Jacobsson, and Rosemarie Fiebranz. 2016. Histsearch - implementation and evaluation of a web-based tool for automatic information extraction from historical text. In HistoInformatics@DH.

Michael Piotrowski. 2012. Natural language processing for historical texts. Synthesis lectures on human language technologies, 5(2):1-157.
Paul Rayson, Dawn E Archer, Alistair Baron, Jonathan Culpeper, and Nicholas Smith. 2007. Tagging the bard: Evaluating the accuracy of a modern POS tagger on early modern english corpora. In Proceedings of the Corpus Linguistics conference: CL2007.

Aynat Rubinstein. 2019. Historical corpora meet the digital humanities: the Jerusalem Corpus of emergent modern Hebrew. Language Resources and Evaluation, 53(4):807-835.

Sebastian Ruder, Ivan Vulić, and Anders Søgaard. 2019. A survey of cross-lingual word embedding models. J. Artif. Int. Res., 65(1):569-630.

Yves Scherrer and Nikola Ljubešić. 2016. Automatic normalisation of the Swiss German ArchiMob corpus using character-level machine translation. In Proceedings of the 13th Conference on Natural Language Processing (KONVENS 2016), pages 248255.

Thomas Scialom, Paul-Alexis Dray, Sylvain Lamprier, Benjamin Piwowarski, and Jacopo Staiano. 2020. MLSUM: The multilingual summarization corpus.

Abigail See, Peter J. Liu, and Christopher D. Manning. 2017. Get to the point: Summarization with pointergenerator networks. In Proceedings of the 55th Annual Meeting of the Association for Computational Linguistics (Volume 1: Long Papers), pages 10731083, Vancouver, Canada. Association for Computational Linguistics.

S.A. South. 1977. Method and Theory in Historical Archeology. Institute for Research on Poverty Monograph Series. Academic Press.

Marcin Sydow, Krzysztof Ciesielski, and Jakub Wajda. 2011. Introducing diversity to log-based query suggestions to deal with underspecified user queries. In International Joint Conferences on Security and Intelligent Information Systems, pages 251-264. Springer.

Hsieh-Chang Tu, Jieh Hsiang, I-Mei Hung, and Chijui Hu. 2020. Docusky, a personal digital humanities platform for scholars. Journal of Chinese History, 4(2):564-580.

Demske Ulrike. 2020. Mercurius-Baumbank (Version 1.1). Universität Potsdam.

Bin Wang, Angela Wang, Fenxiao Chen, Yuncheng Wang, and C.-C. Jay Kuo. 2019. Evaluating word embedding models: methods and experimental results. APSIPA Transactions on Signal and Information Processing, 8:e19.

Peter R White. 1998. Telling media tales: The news story as rhetoric. Department of Linguistics, Faculty of Arts, University of Sydney.

Liang Xu, Xuanwei Zhang, Lu Li, Hai Hu, Chenjie Cao, Weitang Liu, Junyi Li, Yudong Li, Kai 
Sun, Yechen $\mathrm{Xu}$, Yiming Cui, Cong Yu, Qianqian Dong, Yin Tian, Dian Yu, Bo Shi, Jun Zeng, Rongzhao Wang, Weijian Xie, Yanting Li, Yina Patterson, Zuoyu Tian, Yiwen Zhang, He Zhou, Shaoweihua Liu, Qipeng Zhao, Cong Yue, Xinrui Zhang, Zhengliang Yang, and Zhenzhong Lan. 2020. CLUE: A Chinese language understanding evaluation benchmark.

Junnan Zhu, Qian Wang, Yining Wang, Yu Zhou, Jiajun Zhang, Shaonan Wang, and Chengqing Zong. 2019. NCLS: Neural cross-lingual summarization. In Proceedings of the 2019 Conference on Empirical Methods in Natural Language Processing and the 9th International Joint Conference on Natural Language Processing (EMNLP-IJCNLP), pages 30543064, Hong Kong, China. Association for Computational Linguistics.

Junnan Zhu, Yu Zhou, Jiajun Zhang, and Chengqing Zong. 2020. Attend, translate and summarize: An efficient method for neural cross-lingual summarization. In Proceedings of the 58th Annual Meeting of the Association for Computational Linguistics, pages 1309-1321, Online. Association for Computational Linguistics. 


\section{A Output Samples}

\begin{tabular}{ll}
\hline $\mathrm{DE}$ & №11 \\
\hline Story & Die Arbeiten im hiesigen Arsenal haben schon seit langer Zeit nachgelassen, und seitdem die
\end{tabular}

Perser so sehr von den Russen geschlagen worden sind, hört man überhaupt nichts mehr von Kriegsrüstungen in den türkischen Provinzen. Die Pforte hatte nicht geglaubt, daß Rußland eine so starke Macht nach den Ufern des kaspischen Meeres abschicken, und daß der Krieg mit den Persern sobald eine so entscheidende Wendung nehmen würde. Alle kriegerischen Nachrichten, die wir jetzt aus den türkischen Provinzen erhalten, erstrecken sich blos auf die bewaffneten Räuber-Korps, die in der Gegend von Adrianopel noch immer ihren Unfug fortsetzen, der auch wohl nicht eher aufhören wird, bis die Pascha's selbst bestraft worden sind, die die Räuber beschützen. - Im Anfange dieses Monats erschien eine russische Fregatte am Eingange des schwarzen Meeres, ward durch Sturm vor den türkischen Forts vorbei in den Kanal getrieben, ohne daß die Kommandanten dieser Forts ihr den geringsten Widerstand entgegen stellen konnten, und legte sich, Bujukdere gegenüber, vor Anker. Sobald der Kapitän-Pascha dies erfuhr, verfügte er, daß jene Kommandanten abgesetzt werden sollten, und beschwerte sich bei dem hiesigen russischen Minister darüber, daß jenes Kriegsschiff sich unterstanden habe, wider alle Stipulationen der Traktaten in den Kanal einzulaufen. Nachdem aber der Zufall, wodurch dies geschehen ist, näher aufgeklärt war, widerrief der Kapitän-Pascha die Befehle, die gegen die Kommandanten der an dem Kanal gelegenen Forts erlassen wurden. Auch ward auf Ansuchen des russischen Gesandten der gedachten Fregatte aller mögliche Beistand geleistet, um sich repariren, und nach der Krimm, woher sie gekommen war, zurückkehren zu können. - Die Gesandten, welche die Pforte schon seit 2 Jahren nach Wien und Berlin bestimmt hat, sind noch immer hier; dies beweiset, daß alle Schwierigkeiten in Rücksicht dieser Missionen noch nicht gehoben sind Der nach Paris bestimmte türkische Gesandte wird aber, wie es heißt, bald abreisen. Zwei sehr angesehene französische Offiziers, die in türkischen Dienst getreten waren, sind wieder aus demselben entlassen worden.

(The work in the arsenal has for a long time slacked off. And since the Persians were beaten so badly by the Russians, people have heard complete nothing about war armaments in the durkian provinces. The Porte would not have thought that Russia would send such a powerful force to the shores of the Caspian Sea, and that the war with the Persians would at the same time take such a decisive turn. All belligerent news, that we now receive from the Durkian provinces, extends only to the armed robber corps, which are in the area of Adrianopl still continuing their mischief, which is still unlikely to end until the pashas themselves, who protect the robbers, have been punished. - At the beginning of this month a Russian frigate appeared at the entrance to the Black Sea, was driven by a storm past the Durkian forts into the channel, without that the commanders of this fort could oppose it with the slightest resistance, and (the Russian frigate) presented itself across from Bujukdere at anchor. As soon as the captain Pasha found out about this, he decreed that those commanders should be deposed and complained to the local Russian minister about that that that grieg ship had dared to enter the canal, against all stipulations of the tracts. But after the coincidence, by which this happened, had been more clearly clarified, the captain-pasha recalled the orders, which would be enacted against the commanders of the fort on the canal. Also, at the request of the Russian confession, the intended frigate was given all possible assistance in order to repair itself and to be able to return to Grimm, whence it had come. - the confessions, that the gate has set for Vienna and Berlein for two years, are still here; this proves that all difficulties in regard to these missions have not yet been resolved, but the destined-for-Paris Durkian legate will, as it is said, soon be leaving. - two very highly respected French officers, who had entered Durk service, have been dismissed from the same.)

Wie es zwischen Russland und der Türkei lief, war noch unsicher.
(How things would go between Russia and Turkey, was still uncertain.)

IdMap+NORM die [unk] des [unk] zeigen, dass der krieg mit den persern sobald eine so entschiedende wendung nehmen würde . die wendung eines blauen wunders ist nicht nur zu sehen, wie man es weitergeht . ([unk] show that the war with the Persians would very soon take such a decisive turn. The turning point of a blue miracle is not just to see how it goes on.)

UspMap+NORM die arbeiten im arsenal haben schon seite länger zeit nachgelassen, und seitedem die perser so sehr von den russen geschlagen worden sind, hört man überhaupt nichts mehr von kriegrüstungen in den durkischen provinzen .

(The work in the arsenal has for a long time slacked off. And since the persians were beaten so badly by the russians, people have heard complete nothing about war armaments in the durkian provinces.) 
DE №33

Story

ES befindet sich schon etliche Tage hero von der Crone Schweden ein Abgeordneter incognito allhier/ aber noch unbewust in was Negotio. Am verwichenen Montage ist von Ihrer Käyserl. M. an den Abgesandten zu München Herrn Grafen von Königsegg ein Currirer abgeschickt worden/ wie man vernimt/ weilen I. Chur-Fürstl. Durchl. allda gegen I. Käyserl. M. hoch contestirt/ daß Sie Dero Käyserl. und Röm. Reichs Intereße auff alle möglichste Weise befördern helffen/ und auff solche Resolution gedachter Kayserl. Abgesandter von dar seine Reise in auffgetragener LegationsCommißion weiters nehmen wollen/ daß derselbe noch länger allda/ biß der Frantz. Abgesandter von dannen widerum abreisen möge/ verbleiben soll/ damit I. Chur-Fürstl. Durchl. durch erstgedachten Abgesandten nicht zu andern Gedancken kommen möchte. Vorgestern ist der Käys. neulich zu dem Vezier nacher Ofen geschickte Türck. Ober-Dolmetscher/ Herr Minnisky wider zurücke anhero gekommen/ von welchen man vernimt/ daß gedachter Vezier/ wie auch die Baßen von Erlau und Waradein/ sich wegen des beschuldigten Unterschleiffs der Rebellen sehr excusirt/ und negirt/ daß sie bißhero ihrem gethanen Versprächen zu wider die Rebellen in ihren Territoriis wißentlich geduldet hätten/ sondern solches vil mehrers von dem Abassy geschehen wäre/ und habe gedachter Vezier sein hievoriges Versprächen gegen I.K.M. nochmal höchstens contestiren laßen: Demnach aber/ ungeachtet diser Sinceration/ man gewiß weiß/ daß obgedachte Rebellen nicht allein von den Türcken in ihren Gebieten geduldet/ sondern auch bewaffnet worden/ und in neulicher Action die Türcken auff Seiten der Rebellen selbsten darbey gewesen/ also läst es sich nun zu einer würcklichen Ruptur ansehen/ deßwegen auch bey Hofe vil Patenten auff neue Werbungen heraus gegeben werden. (A few days ago there was a member of parliament incognito here from the Royal Family of Sweden, but still unconsciously in some business. On the elapsed Monday, a Currier was sent from their Royal $M$ to the emissaries to monks, Grafen von Königsegg, as people hear, that I. Chur-Fürstl Durchl is contesting against I. Royal $M$, that they help to promote the Royal and Roman Empire interests in every possible way, and that Royal Abgesander who is thinking of such a resolution, wants to continue his journey in the applying Legations Commission, that the same should still remain there for longer, until the Franz Abgesander might leave again, so that I. Chur-Fürstl Durchl through the first envisaged delegate does not want to come to other thoughts. The day before yesterday Käy's new Türck interpreter, Mr. Miniski, who was sent to the Vezier afterwards, has come here, from whom people heard that the intended Vezier, like the bases of Erlau and Waradien, were for the accused hiding of the rebels very excited, and denied that they had so far knowingly tolerated their promise against the rebels in their territories, but that such a thing would have happened much more from the Abassi, and thought Vezier had made his previous promise against the IKM. at most let them contest again: but regardless of this sinceration, people know for sure, the contemplated rebels are not only tolerated by the Tirken in their areas, but also been armed, and in the recent action the Turks were themselves there on the side of the rebels, so it can be viewed now as a real rupture, which is why at court many patents on new recruitments are issued.)

Expert Der Kaiser versuchte, durch Verhandlungen seine Interessen gewährzuleisten. Inzwischen boten die Türken wider Versprechen den Rebellen Unterstützung

(The emperor tried to safeguard his interests through negotiations. Meanwhile Turks broken the promise and provided support to the rebels.)

IdMap+NORM es befindet sich schon etliche tage her von der crone schweden ein abgeordneter inconitum allhier, aber noch unbewusst in was negotio . am verwichenen montage ist von ihrer käyserl . allda gegen $\mathrm{i}$. (A few days ago there was a member of parliament incognito here from the Royal Family of Sweden, but still unconsciously in some business. On the elapsed Monday is from their Royalty all against I.)

UspMap+NORM es befindet sich schon etliche tage her von der crone schweden ein abgeordneter inconitum allhier , aber noch unbewusst in was negotio . am verwichenen montage ist von ihrer käyserl . $m$. an den abgestanden

(A few days ago there was a member of parliament incognito here from the Royal Family of Sweden, but still unconsciously in some business. On the elapsed Monday is from their Royal M to the stale ...) 


\begin{tabular}{|c|c|}
\hline $\mathrm{DE}$ & №34 \\
\hline Story & 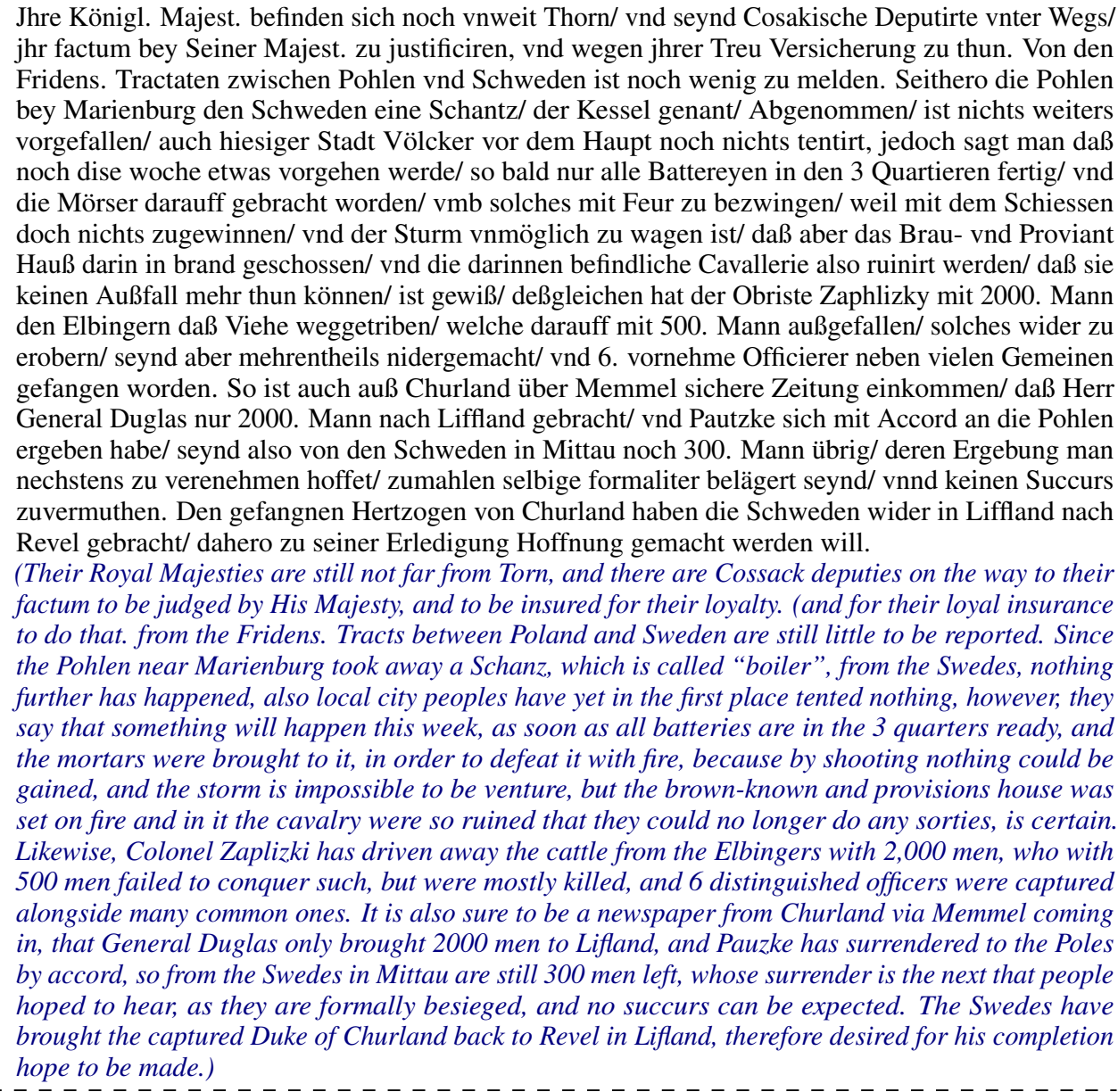 \\
\hline Exp & $\begin{array}{l}\text { Der Krieg zwischen Polen und Schweden dauert an. Von einem Friedensvertrag ist noch nicht der } \\
\text { Rede. } \\
\text { (The war between Poland and Sweden continues. Of the peace treaty is there still no talk.) }\end{array}$ \\
\hline IdMap+NORM & $\begin{array}{l}\text { ihre königl . maiest . befinden sich noch unweit toren, und sind cosakische deputierte unter weg, } \\
\text { ihr factum bei seiner maiest . zu justifizieren, und wegen ihrer treu versicherung zu tun . } \\
\text { (Their Royal Majesties are still not far from Torn, and there are Cossack deputies on the way to their } \\
\text { factum to be judged by His Majesty, and for their loyal insurance to do that.) }\end{array}$ \\
\hline UspMap+NORM & $\begin{array}{l}\text { ihre königl . maiest . befinden sich noch unweit toren, und sind cosakische deputierte unter weg, } \\
\text { ihr factum bei seiner maiest . zu justifizieren, und wegen ihrer treu versicherung zu tun . von den } \\
\text { fridens. } \\
\text { (Their Royal Majesties are still not far from Torn, and there are Cossack deputies on the way to their } \\
\text { factum to be judged by His Majesty, and for their loyal insurance to do that.) }\end{array}$ \\
\hline
\end{tabular}


$\mathrm{DE}$

Story

№39

Heute ist der Kayserl. General-Kriegs-Commissarius, Graf von Nesselrode, mit dem wegen Anweisung derer künftigen Winter-Quartiere abgefasseten Plan von Wien nach dem Kayserl. Haupt Quartier Haydelberg, zu des Printzen Eugenii Hoch-Fürstl. Durchl. wieder zurücke gegangen. Es verlautet dabey, daß die würckliche Einrichtung dererselben viele Schwürigkeiten gefunden habe, und daß verschiedene Reichs-Stände dieselbe von ihren Landen zuförderst abwenden wollen. Mehrere und besondere Umstände sind davon noch nicht bekand. An dem Kayserl. Hofe ist zu Bestreitung derer fortdaurenden schweren Kriegs-Kosten, beschlossen worden, auf verschiedene Waaren, und insonderheit auf den Wein $u$. Fische einen neuen Impost zu legen, ob aber auch künfftig das Silber-Geschirre in die Kayserl. Müntze dürfte gefordert werden, wie bisher verlauten will, solches ist noch zweyfelhafftig, inzwischen wird mit Eintreibung eines sogenandten Subsidii präsentanti, wobey alle vermögende Leute zur Anticipation eines nach eines jedweden Vermögen eingerichteten Quanti angehalten werden, und dargegen aus der Kayserl. Banco in 3. Jahren zahlbare Banco-Obligationen, nebst 5. pro Cent Interesse erhalten, nicht nur zu Wien fortgefahren, sondern es soll auch dergleichen in allen Kayserl. Erb-Landen, das eintzige Königreich Ungarn ausgenommen, dessen Privilegia solches nicht verstatten, eingeführet werden. Man hat aus Italien Nachricht, daß die Alliirten ten zwischen der Etsch und Adige nicht nur eine starcke Linie gezogen haben, um denen Deutschen den Rück-Weg nach dem Mantuanischen gäntzlich zu benehmen, sondern sich auch gegen das Triedentinische ziehen, und daselbst einbrechen wollen. Sonst weiß man, daß der Erb-Printz und numehro regierende Durchl. Hertzog, Carl, von Braunschweig-Wolfenbüttel, die gesuchte Veniam ätatis von Ihro Kayserl. Maj. auf das erstattete Reichs-Hofe-Raths-Gutachten erhalten habe.

(Today the Lord General-Krügs-Commissarius, Count of Nesselbrote, is with with the plan, which is drawn up according to the instructions for their future winter quarters, from Vienna to the emperor's headquarter, Heidelberg, to the Prince Eugenii Hoch-Fürstl Durchl. Again, it passed back. It is said that the real institution of the same has found many difficulties, and that the various imperial estates want to turn them away from their lands first of all. Several and special circumstances are not yet known about. At the Royal Court it was decided to pay for the continuing heavy Krügs costs, on various goods, and in particular on the wine and the Fish a new tax to put, but whether in the future the silver dishes in the Royal Coin should be required, as has been so far announced, this is still doubtful. In the meantime with the collection of a so-called Subsidium Presentanti, (in which all wealthy people are encouraged to anticipate a Quanti set up according to one's every wealth, and on the other hand from the Royal Bank received in 3 years payable bank debts, plus 5th interest per cent,) not only carried on in Vienna, but the same should be introduced in all Royal Hereditary Lands, the only kingdom of Hungary, with the exception of whose privileges do not permit such. People had news from Italy that the Allies had not only drawn a strong line between the Etsch and the Adige in order to deprive the Germans of the way back to Mantuan entirely, but also oppose the Tridentine and want to break in there. Otherwise knowing people that the Hereditary Prince and now ruling Highness Duke, Carl, von Braunschweig-Wolfenbutel, who have sought for Veniam ätatis from their Royal May, have received the submitted Reichs-Hofe-RAts report.)

Expert Der Kaiser ließ einrichtungsbezogene, finanzielle, militärstrategische und personelle Anordnungen vornehmen, um den Krieg weiterzuführen.

(The emperor had ordered to make facility-related, financial, military-strategic and personnel arrangements in order to continue the war.)

IdMap+NORM heute ist der kaiserl . general-krügs-commissarius, graf von nesselbrote , mit dem wegen angeweisung derer künftigen winter-quartiere abgefassten plan von wie nach dem kaiserl . haupt quartier heidelberg, zu des prinzen eugenii hoch-fürstl .

(Today the Lord General-Krügs-Commissarius, Count of Nesselbrote, is with with the plan, which is drawn up according to the instructions for their future winter quarters, from Vienna to the emperor's headquarter, Heidelberg, to the Prince Eugenii Hoch-Fürstl.)

UspMap+NORM heute ist der kaiserl . general-krügs-commissarius, graf von nesselbrote , mit dem wegen angeweisung derer künftigen winter-quartiere abgefassten plan von wie nach dem kaiserl . haupt quartier heidelberg, zu des prinzen eugenii hoch-fürstl .

(Today the Lord General-Krïgs-Commissarius, Count of Nesselbrote, is with with the plan, which is drawn up according to the instructions for their future winter quarters, from Vienna to the emperor's headquarter, Heidelberg, to the Prince Eugenii Hoch-Fürstl.) 


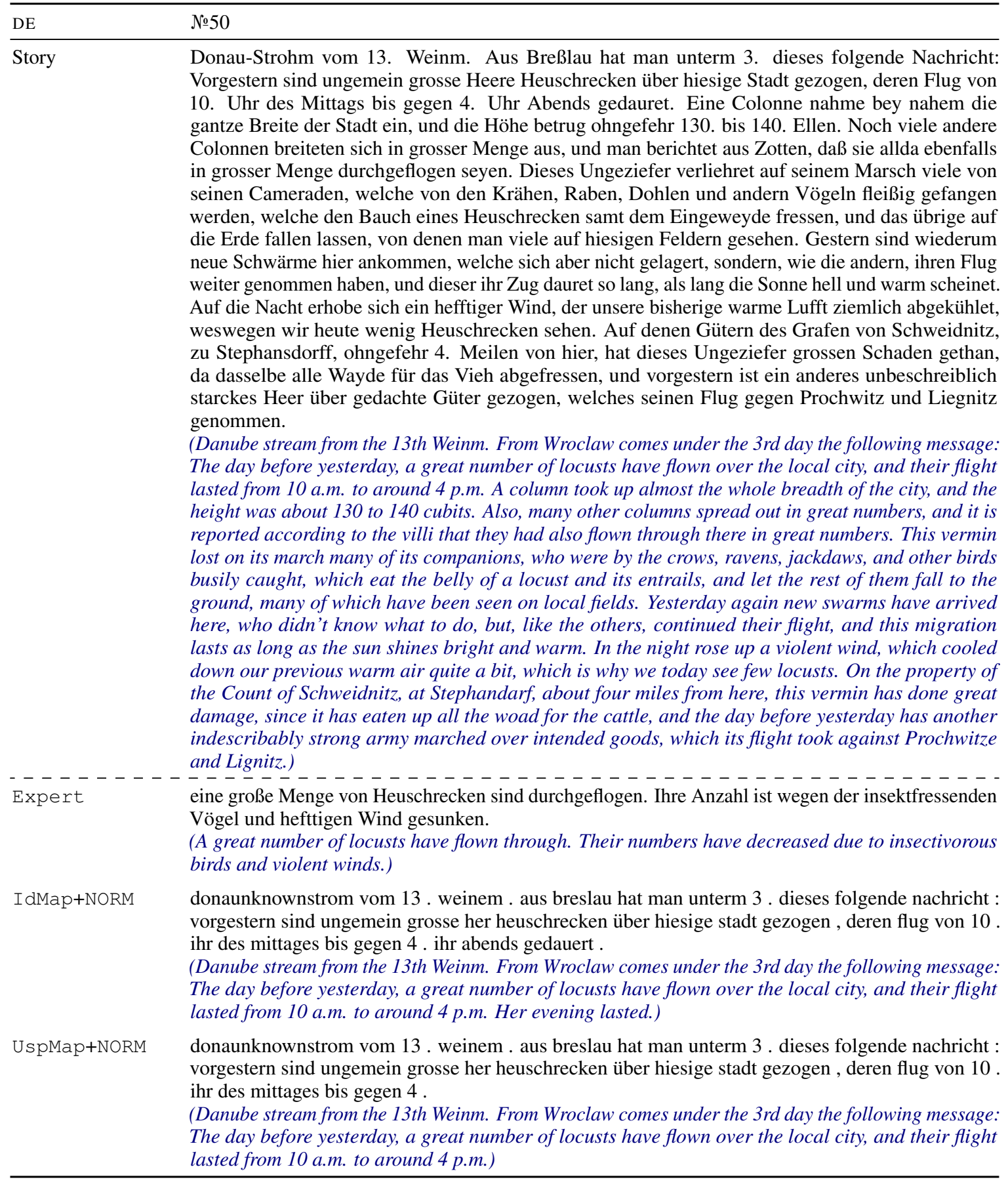




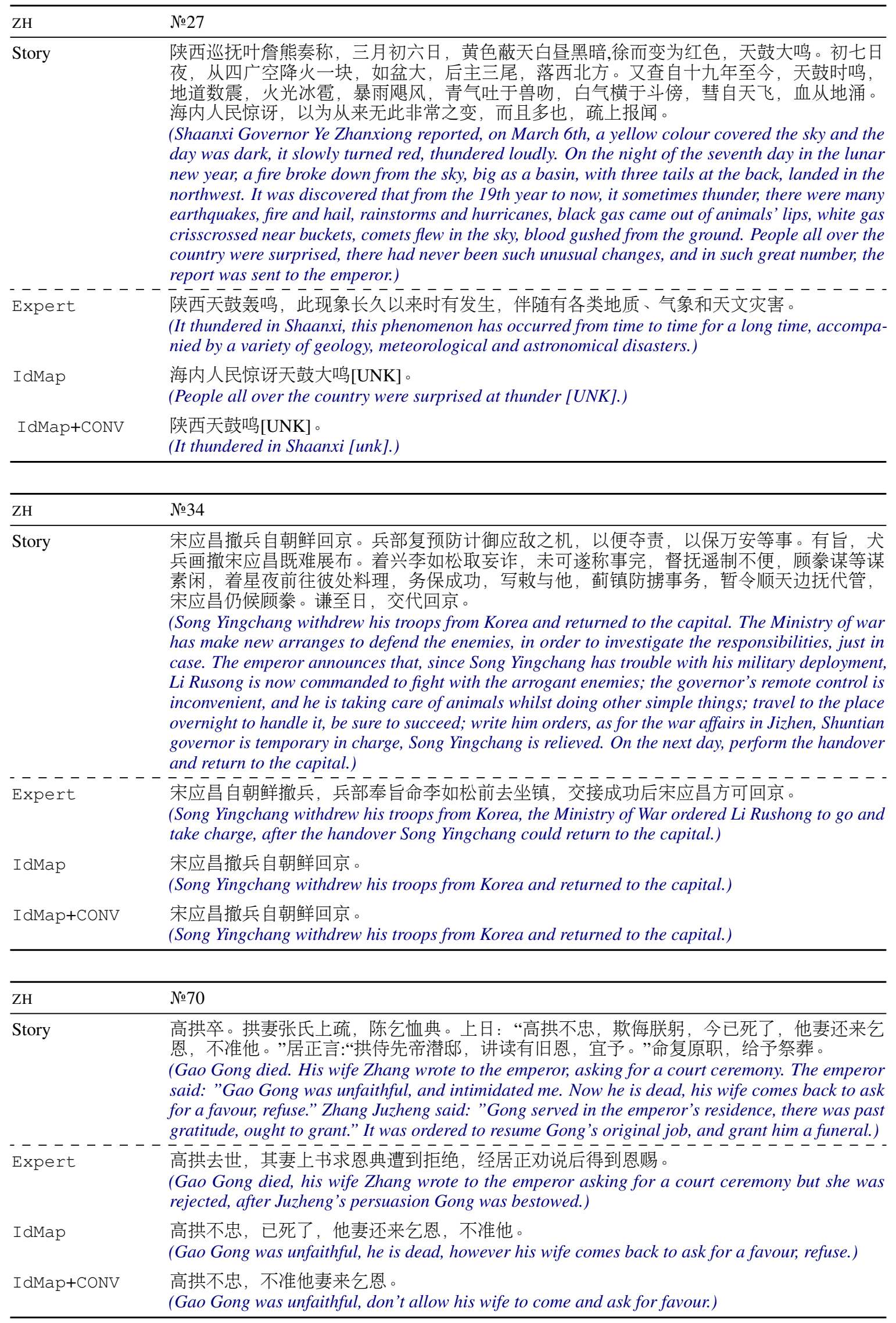




\begin{tabular}{ll}
\hline ZH & №78 \\
\hline Story & 黄台吉裴封顺义王。礼部等部尚书等官徐学谟等题称, 北虏求嗣封爵, 称黄台吉傈俺答嫡 \\
& 长男, 应嗣王号, 舍力克台吉傈黄台吉的男, 应袭龙湖将军职衔。报可。 \\
& (Huangtaiji was granted the title of King Shunyi. Xu Xuemo and others who were officials of the \\
& Ministry of Rites said, enemy from the north asked to be offered hereditary peerages, Huangtaiji \\
& was Anda's eldest son, he should inherit the title of king, Sheliketaiji was Huangtaiji's eldest son, he \\
& should inherit the rank of general Longhu. The suggestion was approved.)
\end{tabular}


B Sample of Wanli Gazette (Scanned) Copies

\section{政焦花}

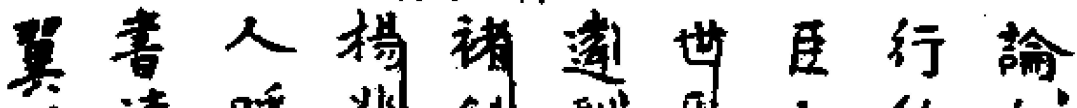

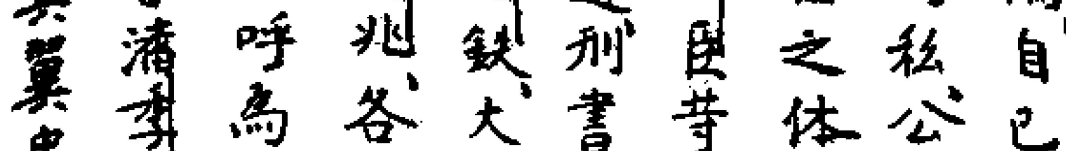

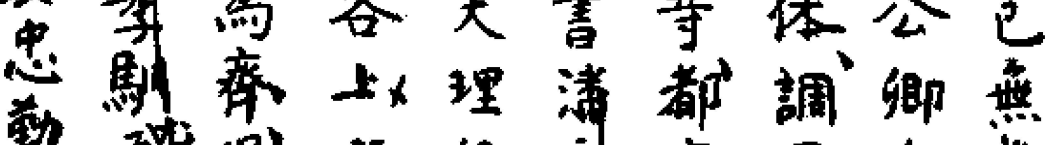

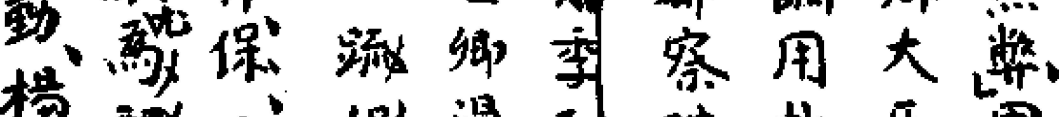

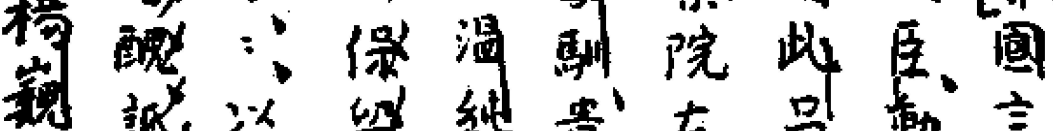

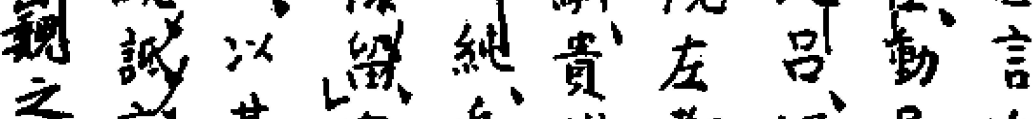

㑆䚺其内兵开都次兄近

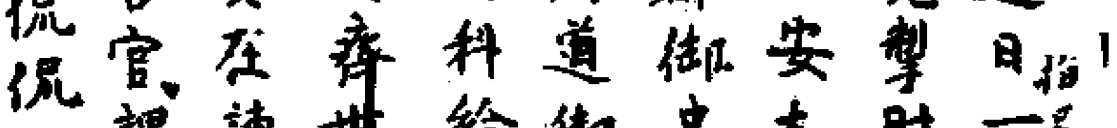

正揞諌世给御史大肘一天

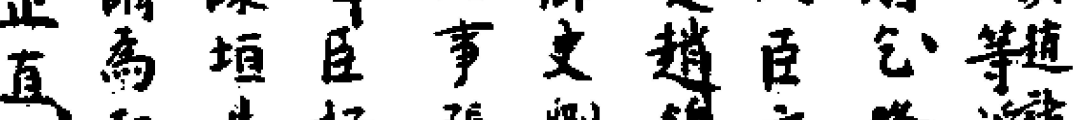

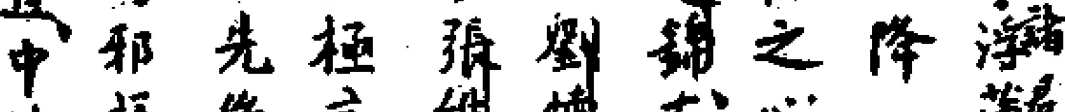

外珴俊言维慎左心蒲名

犬蜂惟三新恕副各温䧼

小起以大更刑都求首進

諸图保国侍侍御罪勉好

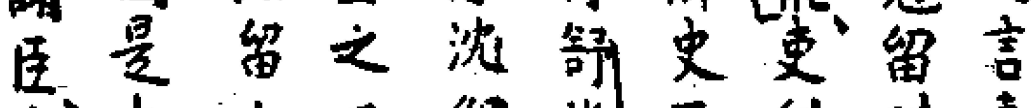

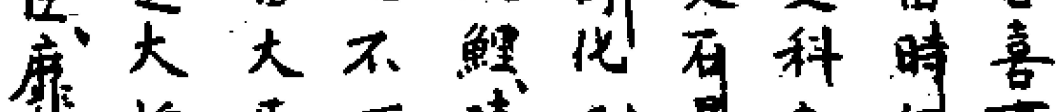

不播臣可陵工軎都行事：

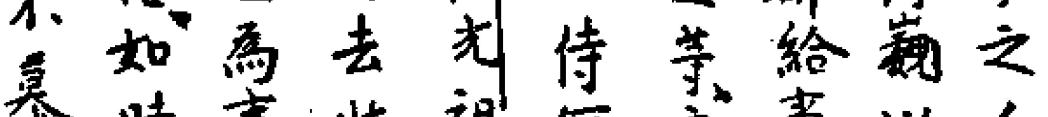

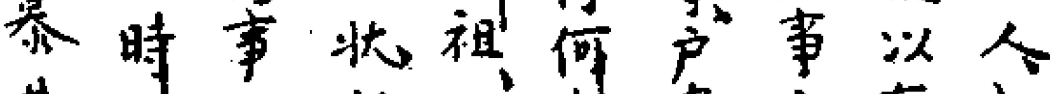

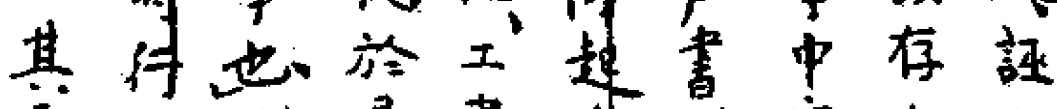

离之刑是書㧹王率大卡 